Aletria, Belo Horizonte, v. 29, n. 3, p. 229-248, 2019

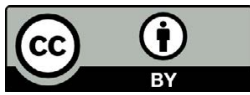

\title{
Sobre a dificuldade de nomear a produção do presente: Rancière e Laddaga e os regimes das artes
}

\section{On the Difficulty of Naming a Production of the Present: Rancière and Laddaga and the Regimes of the Arts}

\author{
Ieda Magri \\ Universidade Estadual do Rio de Janeiro (UERJ), Rio de Janeiro, Rio de Janeiro / Brasil \\ iedamagri@yahoo.com.br
}

Resumo: Este artigo propõe uma reflexão sobre algumas formas de pensar e nomear a produção artístico-literária do presente a partir do texto "Em que tempo vivemos?" de Jacques Rancière. Assim, buscamos respostas às implicações de se pensar o tempo em que vivemos como um tempo pós. Um tempo que, para Rancière, precisa ser visto como não-homogêneo, um tempo em que se produz rupturas e intervalos, fazendo deixar de coincidir o tempo global e o tempo individual da pessoa. Para Rancière, o nosso tempo pós, no que diz respeito ao modo de ler a história da arte, ainda é o tempo do Regime Estético, que sucedeu outros dois Regimes, o Ético e o Poético ou Representativo. Reinaldo Laddaga, argentino radicado nos EUA, discorda de Rancière e vê ruptura onde este vê continuidade. Assim, para Laddaga, depois do Regime Estético, teríamos entrado no que ele chama de Regime Prático das Artes. Essa discussão nos faz ver o que esses termos representam em contraposição à ideia de Modernismo e Pós-modernismo.

Palavras-chave: literatura contemporânea; modernidade; pós-modernidade; contemporâneo; regimes das artes; Rancière; Laddaga.

Abstract: We propose a reflection on some ways of thinking and naming artisticliterary production of the present from the text "In what time do we live?", by Jacques Rancière. Thus, we seek answers to the implications of thinking about the time in which we live as a post time. A time that, for Rancière, must be seen as non-homogeneous, a time in which ruptures and intervals occur, making the global time and individual time not matching once again. For Rancière, our post time, as far as the way of reading art history is concerned, is still the time of the Aesthetic Regime, which succeeded other two Regimes, the Ethical and the Poetic or Representative. Reinaldo Laddaga, an 
Argentinean who settled in the USA, disagrees with Rancière and sees rupture where he sees continuity. Thus, for Laddaga, after the Aesthetic Regime, we would have entered what he calls the Practical Regime of the Arts. This discussion makes us see what these terms represent in contrast to the idea of Modernism and Postmodernism.

Keywords: contemporary literature; modernity; postmodernity; contemporary; regimes of the arts; Rancière; Laddaga.

No texto "Em que tempo vivemos?" (2014), Rancière vê a permanência de dois aspectos da grande narrativa marxista em todas as interpretações sobre o mundo contemporâneo e suas consequências políticas, inclusive na maneira de conceber uma história da arte. O que se perdeu, ou seja, o que chegou ao fim, diz ele, foi apenas a utopia, a crença e a fé no progresso como educação e aperfeiçoamento do mundo e do homem. Não se acredita mais no possível da transformação e na revolução. Os dois aspectos, as duas tramas de concepção do mundo e do tempo que permanecem da narrativa marxista moderna seriam a da necessidade histórica, que concebe um futuro entregue ao próprio mercado, que tudo regeneraria - o que dá origem à narrativa da repetição; e a da necessidade de atuar como forma de produzir inteligibilidade do tempo e do mundo vivido. Nessa trama, a da decadência, a sensação é de iminente catástrofe, a ideia de apocalipse, de mundo onde os recursos naturais acabam - a narrativa do desastre, que ressalta a tendência à resistência à instauração do mercado global. Nas duas versões, é impossível fugir desse tempo global, que tudo toma. Um tempo homogêneo.

O ponto cego dos discursos sobre o nosso tempo, segundo Rancière, é a pressuposição de uma identidade imediata entre o tempo global e o tempo das pessoas, construídos como o tempo da produção capitalista (global) e o tempo do consumo individual. Essa identidade é apresentada como "o reinado do presente absoluto em que tudo - produção, consumo, informação, produção de imagens - se dá na mesma velocidade acelerada." Seria preciso perceber que nosso tempo não é definido apenas pela velocidade do capital. É definido também pelas instituições que fazem coincidir ou não os tempos. Assim, a política regularia o tempo determinando suas divisões com o cronograma das eleições - o tempo da política é o tempo do Estado; o sistema educacional, assim como outras

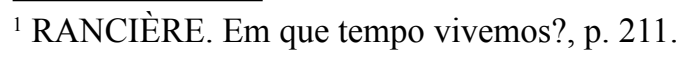


instituições supranacionais, harmonizaria o tempo da economia, das instituições e das pessoas; e os meios de comunicação construiriam uma barreira entre os que sabem e os que não sabem, fazendo divergir os tempos, na medida em que estruturariam a distribuição do cotidiano sensível:

É por isso que, em minha opinião, uma saída para essa lógica seria uma saída de seu tempo, uma saída da trama da homogeneidade do tempo e da incapacidade daqueles que nele vivem. Essa saída tem que questionar a tese da homogeneidade do tempo. Não existe um processo global que submeta a suas regras todos os ritmos do tempo individual e do tempo coletivo. Há vários tempos em um só tempo. Existe, decerto, uma forma dominante de temporalidade, um tempo "normal" que é o tempo da dominação. A dominação lhe proporciona suas divisões e seus ritmos, suas agendas e suas programações a curto e a longo prazos: o tempo de trabalho, do lazer e do desemprego, das campanhas eleitorais, dos cursos de graduação na educação etc. A dominação tende a homogeneizar todas as formas de temporalidade sob seu controle, definindo com isso em que consiste o presente de nosso mundo, quais futuros são possíveis e quais pertencem, definitivamente, ao passado - o que significa que são impossíveis. É isso que quer dizer "consenso": o monopólio das formas de descrição do perceptível, do imaginável e do factível. No entanto, existem outras formas de temporalidade, formas dissensuais que criam distensões e rupturas naquela temporalidade. ${ }^{2}$

Nesse texto, Rancière está interessado em mostrar "formas dissensuais de temporalidade" naquilo que os trabalhadores fazem com seu tempo livre. A reapropriação desses "intervalos de subjetivação" produz "formas de ruptura", o que faz "a temporalidade aparentemente superada da emancipação reaparecer na ordem do dia". ${ }^{3} \mathrm{O}$ trabalhador não é mais redutível a uma única forma de subjetividade porque se apropria do tempo e faz o seu próprio tempo de trabalho. Outra maneira de produzir "formas dissensuais de temporalidade" é a interrupção na máquina social produzida pelos movimentos sociais. $\mathrm{O}$ que especialmente o interessa

\footnotetext{
${ }^{2}$ RANCIÈRE. Em que tempo vivemos?, p. 214-215.

${ }^{3}$ RANCIÈRE. Em que tempo vivemos?, p. 217.
} 
é a impossibilidade de mapear a heterogeneidade, a impossibilidade de decompor quem ali se reuniu em grupos de identidade.

Já em "Paradoxos da arte política", de $O$ espectador emancipado (2014), para melhor esclarecer o que entende por dissenso, Rancière traz a definição de consenso:

A palavra consenso significa muito mais que uma forma de governo "moderno" que dê prioridade à especialidade, à arbitragem e à negociação entre os "parceiros sociais" ou os diferentes tipos de comunidade. Consenso significa acordo entre sentido e sentido, ou seja, entre um modo de apresentação sensível e um regime de interpretação de seus dados. Significa que, quaisquer que sejam nossas divergências de ideias e aspirações, percebemos as mesmas coisas e lhes damos o mesmo significado. $O$ contexto de globalização econômica impõe essa imagem de mundo homogêneo no qual o problema de cada coletividade nacional é adaptar-se a um dado sobre o qual ela não tem poder, adaptar a ele seu mercado de trabalho e suas formas de proteção social. ${ }^{4}$

A discussão sobre consenso e dissenso diz respeito a uma polêmica com Habermas, melhor apresentada no texto "O dissenso", publicado no Brasil em A crise da razão (1996), livro organizado por Adauto Novaes:

É isso o que chamo de dissenso: não um conflito de pontos de vista nem mesmo um conflito pelo reconhecimento, mas um conflito sobre a constituição mesma do mundo comum, sobre o que nele se vê e se ouve, sobre os títulos dos que nele falam para ser ouvidos e sobre a visibilidade dos objetos que nele são designados. O dissenso não é a guerra de todos contra todos. Ele dá ensejo a situações de conflito ordenadas, a situação de discussão e de argumentação. Mas essas discussões e argumentações são de um tipo particular. Com efeito, devem primeiro constituir o mundo no qual elas são argumentações. É preciso primeiro provar que há algo a argumentar, um objeto, parceiros, um mundo que os contém. E é preciso prová-lo na prática, ou seja, fazendo como se esse mundo já existisse. ${ }^{5}$

\footnotetext{
${ }^{4}$ RANCIÈRE. O espectador emancipado, p. 67.

${ }^{5}$ RANCIÈRE. O dissenso, p. 374.
} 
Mais adiante dirá que essa forma de dialogismo se distingue do modelo habermasiano da razão comunicativa justamente porque, para que haja contradição performativa, é preciso que a situação de fala já esteja constituída com seus locutores e seus objetos. E o próprio do dissenso político é que pelo menos um dos elementos da cena não está constituído. É a própria constituição do sujeito político, a construção pela fala de outro mundo possível que caracteriza o dissenso.

Mas o que isso tem a ver com as artes no nosso tempo? Essas políticas também podem ser vistas como meios de lidar com a convergência e a divergência dos tempos. Em "Em que tempo vivemos?", Rancière fala de três figuras principais que ilustram esses meios: 1) O filme Um homem com uma câmera na mão, de Dziga Vertov, de 1929, que reuniu no mesmo ritmo os movimentos de uma bailarina, os gestos de uma mulher trabalhando, o tráfego nas ruas, etc. A sincronia desses movimentos constitui um tempo homogêneo sem interrupções, sem diferença entre vida, trabalho e lazer. O comunismo como sincronismo de todos os movimentos. 2) O teatro de Bertold Brecht, que ele situa em 1942, com Mãe Coragem, como política oposta, que ressalta a divergência dos tempos e tenta construir um tempo específico em que o tempo global pode ser modelado e tornado inteligível: mostrar a dominação da lógica do dinheiro sobre a mãe coragem. A crítica de Rancière é especialmente contundente a essa arte engajada: ela acompanharia o exercício de dominação enquanto pretende revelar os segredos dessa dominação a pessoas que não ignoram coisa alguma sobre seus segredos. Ela requer uma eficácia política, à qual em "Paradoxos da arte política", Rancière opõe uma eficácia estética.

Se a experiência estética toca a política, é porque também se define como experiência de dissenso, oposta à adaptação mimética ou ética das produções artísticas com fins sociais. As produções artísticas perdem funcionalidade, saem da rede de conexões que lhes dava uma destinação antevendo seus efeitos; são propostas num espaço-tempo neutralizado, oferecidas igualmente a um olhar que está separado de qualquer prolongamento sensório-motor definido. $O$ resultado não é a incorporação de um saber, de uma virtude ou de um habitus. Ao contrário, é a dissociação de certo corpo de experiência. ${ }^{6}$

${ }^{6}$ RANCIÈRE. O espectador emancipado, p. 60. 
Tanto em "Em que tempo vivemos?" como em "Paradoxos da arte política", Rancière cita como exemplo de eficácia estética, ou de "terceira política da arte", em contraposição aos modelos de Vertov e de Brecht, o cinema de Pedro Costa. Essa terceira política da arte seria "aquela que entrelaça diferentes tempos no interior de pequenas máquinas ou dispositivos que constroem outras possibilidades de examinar o presente, a certa distância da convergência unânime dos tempos e da construção crítica de sua divergência."7 Ele propõe chamá-las, a partir de Foucault, de "heterocronias", combinações de tempos incompatíveis, em paralelo com heterotopias, combinações de espaços incompatíveis. O exemplo que dá é o episódio final do filme Juventude em marcha, de 2006. E ele justifica assim sua escolha:

O episódio nos apresenta um entrelaçamento de tempos estruturados pela conjunção de dois tempos incompatíveis: o tempo do documentário e o tempo da tragédia; o tempo do trabalhador imigrante, vindo de longe, que, no fim de uma vida de trabalho e desemprego, obteve uma cédula de identidade e um apartamento com água, gás e eletricidade, e o tempo do morto-vivo que circula pelos subúrbios de nossas cidades e pelo reino das sombras. Tal conjunção se condensa na carta de amor que Lento recita: Pedro Costa a compôs juntando fragmentos de cartas escritas por trabalhadores imigrantes e fragmentos da última carta enviada pelo poeta francês Robert Desnos a caminho do campo de concentração de Terezin e da morte. Essa montagem de tempos compõe uma cena do Juízo Final, mas esse juízo final não é uma narrativa de desastre. Pelo contrário é uma forma de suspensão das tramas habituais que absorve todas as situações no processo global e priva aqueles que vivem em nosso tempo da capacidade de compreendê-lo. Uma heterocronia é uma redistribuição de tempos que inventa novas capacidades de definir um presente. $^{8}$

\footnotetext{
${ }^{7}$ RANCIÈRE. Em que tempo vivemos?, p. 220.

${ }^{8}$ RANCIÈRE. Em que tempo vivemos?, p. 221-222.
} 
Em "Paradoxos da arte política", Rancière diz:

Pedro Costa põe assim em ação uma política da estética tão afastada da visão sociológica segundo a qual "política" da arte significa explicação de uma situação - ficcional ou real - pelas condições sociais, quanto da visão ética que pretende substituir a "impotência" do olhar e da palavra pela ação direta. Ao contrário, o que está no cerne de seu trabalho é o poder do olhar e da palavra, o poder do suspense que eles instauram. Pois a questão política é, em primeiro lugar, a capacidade de corpos quaisquer se apoderarem de seu destino. ${ }^{9}$

Uma eficácia estética, portanto, que é política em si mesma. E mais adiante: “Mas essa 'estetização' significa justamente que o território intelectual e visualmente banalizado da miséria e da margem é devolvido à sua potencialidade de riqueza sensível compartilhável."10

Rancière está interessado em pensar a política das artes do nosso tempo enquanto eficácia estética. Nos lembra, a propósito, quando fala de uma política da literatura, que a literatura faz política enquanto literatura, assim como o filme de Pedro Costa faz política enquanto filme, enquanto arte.

\section{O tempo em que vivemos: rupturas, formas de resistência à homogeneidade, a exigência de ver no escuro}

Busquei, nos parágrafos anteriores, costurar dois textos de Rancière que dão conta do tempo em que vivemos enquanto o tempo do Regime Estético das artes para melhor evidenciar as consequências da percepção e da leitura do tempo presente em relação com nossos modos de ler, produzir e interpretar as produções artísticas.

Quando se parte para uma investigação do contemporâneo, enquanto o tempo em que vivemos e também - como veremos mais adiante - enquanto regime das artes, há uma reivindicação constante em buscar rupturas no grande tempo ou no grande panorama que aparece como unidade, como o grande intransponível fosso do presente inundado da luz cegante do discurso do progresso ou da catástrofe.

\footnotetext{
${ }^{9}$ RANCIÈRE. O espectador emancipado, p. 78.

${ }^{10}$ RANCIÈRE. O espectador emancipado, p. 78.
} 
Agamben, por exemplo, no já clássico "O que é o contemporâneo" (2009), lê o contemporâneo como um modo específico de se estar no tempo: o contemporâneo é aquele que não coincide com o seu tempo, que é "inatual". Assim como Rancière, porém a partir de outra perspectiva, Agamben também reivindica a produção de uma discrepância que poderia ser capaz de dar a ver algo que permaneceria no escuro para quem está completamente imerso no próprio tempo. Também aqui podemos ler a não-coincidência entre o tempo do mundo, percebido como homogêneo, e o tempo da pessoa, capaz de furar, de rasurar esse tempo.

Para Didi-Huberman, no também bastante conhecido Sobrevivência dos vaga-lumes (2011), o nosso tempo é o tempo das luzes, do clarão dos holofotes. Seria necessário não se deixar ofuscar pelas luzes para conseguir ver a intermitência dos pequenos vaga-lumes que, para ele, não deixam de existir no fascismo contemporâneo tal qual apresentado por Pasolini - o fascismo da sociedade de consumo - mas que se retiram para lugares menos iluminados. É outra maneira, mais poética, de se reivindicar a mesma necessidade: a de produzir brechas, rupturas, intervalos, interrupções. Se Agamben e Rancière, porém, fazem uma leitura do contemporâneo a partir da ideia de tempo, Didi-Huberman, pensa a partir de espaço, opondo imagem a panorama ou horizonte.

O contemporâneo, assim, naquilo que me interessa investigar no presente artigo, tem a ver com: a) o tempo histórico do qual fazemos parte; é um recorte, o atual, o tempo em que vivemos; b) a impossibilidade de se fazer uma definição precisa do presente e que leva a essa necessidade de se produzir permanentemente novas definições e rupturas que produzam dissenso no tempo aparentemente homogêneo da globalização; e c) uma nova forma de nomear e pensar o depois do moderno; substituição do termo pós-moderno e, nesse sentido, indicaria uma impossibilidade de se identificar uma tendência, escola ou movimento no campo dar artes, onde reinaria uma pluralidade de poéticas, concepções e usos da arte.

As primeiras duas formas de percepção do contemporâneo foram investigadas de maneira sucinta até aqui e, ainda que tanto Rancière quanto Laddaga não pensem a partir do contemporâneo como conceito, no próximo tópico gostaria de partir do que ambos pensam como Regimes das artes para depois voltar ao seu enredamento com o contemporâneo. 


\title{
Dos regimes da arte
}

Na seção "Dos regimes da arte e do pouco interesse da noção de modernidade", de A partilha do sensivel (2005), Rancière defende que a ideia de modernidade encobre um tipo específico de ligação entre modos de produção, formas de visibilidade e modos de conceituação destas. Os modos de produzir, de dar a ver e de conceituar são distintos na história ocidental. Ele a divide em três grandes períodos, três diferentes paradigmas, três regimes: o Ético, com Platão; o Poético ou Representativo, com Aristóteles, e o Estético, a partir do Romantismo Alemão e do Realismo. No primeiro, a arte é definida por um modo de ser (o problema da verdade, do que é ou não é arte, de sua função); no segundo por um modo de dar a ver (o feito do poema, a fabricação de uma intriga, a fabricação de uma mentira bela, a representação de homens agindo segundo uma hierarquia de temas e de gêneros) e no terceiro por um modo de ser sensível.

Rancière dirá que o Regime Estético é "o verdadeiro nome de modernidade":

\begin{abstract}
Pode-se dizer que o Regime Estético das artes é o verdadeiro nome daquilo designado pela denominação confusa de Modernidade. Mas "Modernidade" é mais do que uma denominação confusa. Em suas diferentes versões "Modernidade" é o conceito que se empenha em ocultar a especificidade desse regime das artes e o próprio sentido da especificidade dos regimes da arte. Traça, para exaltá-la ou deplorá-la, uma linha simples de passagem ou de ruptura entre o antigo e o moderno, o representativo e o não representativo ou o antirrepresentativo. ${ }^{11}$
\end{abstract}

Rancière chama a atenção para o uso do conceito de Modernidade como passagem para o não-figurativo na pintura e critica essa historicização simplista. Ou seja, a Modernidade simplesmente como o antimimético, o antirrepresentativo. Ele também conceitua o Regime Estético em sua diferença em relação ao Regime Representativo, porém não no sentido de não-figuração, mas de entrada democrática do qualquer um no campo das artes, como fica melhor explicitado no texto "Política da Literatura". Uma passagem ajuda a compreender o específico do Regime Estético das artes:

${ }^{11}$ RANCIÈRE. A partilha do sensivel, p. 33. 
A literariedade que tornou possível a literatura como nova forma da arte da palavra não é nenhuma propriedade específica da linguagem literária. Pelo contrário, ela é a democracia radical das letras, da qual qualquer um pode se aproveitar. A igualdade dos temas e das formas de expressão que define a novidade literária se acha ligada à capacidade de apropriação do leitor qualquer. ${ }^{12}$

Essa igualdade dos temas e das formas de expressão, conquista já do romance realista de Balzac e radicalizada com Flaubert e com Baudelaire é a entrada em cena do qualquer um, do anônimo, das personagens de baixo escalão que obriga a crítica a rever todo o seu sistema de reflexões com base em oposições como melhor/pior, alto/ baixo. A própria literatura inicia o que o discurso teórico, então, poderá designar como Regime Estético das artes, "aquele que identifica a arte no singular", ${ }^{13}$ desobrigada de qualquer regra específica, modelo, hierarquia de temas ou gêneros.

Ainda seguindo "Dos regimes da arte e do pouco interesse da noção de Modernidade", fica patente a ruptura com o regime anterior: "A esse regime representativo contrapõe-se o regime da arte que se denomina estético. Estético porque a identificação da arte nele não se faz mais por uma distinção no interior das maneiras de fazer, mas pela distinção de um modo de ser sensível próprio aos produtos da arte". ${ }^{14} \mathrm{E}$ mais adiante, para mostrar uma especificidade que aumenta a distância com relação ao Regime Representativo, cuja tônica é justamente a forte hierarquia dos gêneros e dos temas - basta pensar que a tragédia representa os homens melhores do que eles são e a comédia, piores, na definição de Aristóteles na Poética - ele agrega:

O Regime Estético das artes é aquele que propriamente identifica a arte no singular e desobriga essa arte de toda e qualquer regra específica, de toda a hierarquia de temas e gêneros e artes. Mas, ao fazê-lo, ele implode a barreira mimética que distinguia as maneiras de fazer a arte das outras maneiras de fazer e separava suas regras da ordem das ocupações sociais. Ele afirma a absoluta singularidade da

\footnotetext{
${ }^{12}$ RANCIÈRE. Política da literatura, p. 13.

${ }^{13}$ RANCIÈRE. Política da literatura, p. 12.

${ }^{14}$ RANCIÈRE. A partilha do sensivel, p. 32.
} 
arte e destrói ao mesmo tempo todo critério pragmático dessa singularidade. Funda, a uma só vez, a autonomia da arte e a identidade de suas formas com as formas pelas quais a vida se forma a si mesma. O estado estético schilleriano - que é o primeiro e, em certo sentido, inultrapassável - manifesto desse regime marca bem essa identidade fundamental dos contrários. O estado estético é pura suspensão, momento em que a forma é experimentada por si mesma, o momento de formação de uma humanidade específica. ${ }^{15}$

O problema com o conceito de Modernidade é que ele foi reduzido à tradição do novo e, assim, "ao vazio de sua autoproclamação". ${ }^{16} \mathrm{~A}$ vantagem de se pensar em termos de Regime Estético das artes é que se recuperaria, ao invés de esconder, a condição que lhe é própria, retirando-a da falsa oposição entre antigo e moderno. E já antecipando o que depois iria aparecer no texto "Em que tempo vivemos?", ele dirá aqui que "o conceito de modernidade que se fixou está ligado a um sentido único quando a temporalidade própria ao Regime Estético é de uma co-presença de temporalidades heterogêneas." 17

O Regime Estético não separa tempos como quando pensamos em Moderno e Pós-moderno. Para Rancière não houve mudança de paradigma depois do Romantismo Alemão e do Realismo, que, para ele, apenas intensificou aquilo que já estava previsto na ruptura romântica. Para Rancière, o Pós-modernismo foi a maneira como alguns artistas e pensadores se deram conta daquilo que foi - depois de seu fracasso - o modernismo em suas duas grandes narrativas: a de fundar o próprio da arte e a teologia simples da evolução e da ruptura históricas. Compreendese nesse texto, na verdade uma entrevista, aquilo que fundamenta "Em que tempo vivemos?": não haveria necessidade dessa narrativa do pós, pois não há fim e recomeço. Depois do fim, permanecem as mesmas questões, despidas porém do caráter humanitarista que a modernidade tomou como um dos seus fundamentos, a formação estética do homem. Despida da utopia da transformação.

Em Estética da emergência (2012), Reinaldo Laddaga, partindo dos regimes das artes de Rancière, sustenta a emergência de uma nova

\footnotetext{
${ }^{15}$ RANCIÈRE. A partilha do sensivel, p. 33-34, grifos do autor.

${ }^{16}$ RANCIÈRE. A partilha do sensivel, p. 37.

${ }^{17}$ RANCIÈRE. A partilha do sensivel, p. 37.
} 
cultura das artes. Ao se perguntar o que seria um regime da arte, ele associa o termo ao de "episteme", de Foucault, e ao de "paradigma", de Thomas Kuhn: "um marco geral que é o fundo sobre o qual as operações particulares adquirem perfil e significado". ${ }^{18}$ Assim, ele detecta, também em sintonia com a Estética Relacional, a emergência de uma nova cultura das artes que, seguindo a terminologia de Rancière, chamará de Regime Prático. Esse novo regime estaria marcado por uma transição na qual um grande número de artistas (e de não artistas) reage ao esgotamento do paradigma moderno e, segundo ele, ao insuficiente tipo de resposta do que se chamou até a década de 1990 de Pós-modernismo. Esse regime interroga as questões chave da modernidade artística: a demanda de autonomia, a crença nos valores estéticos e a capacidade da arte de propor respostas para o sentido do mundo, etc. Uma das características fundamentais está na saída do fechamento disciplinar e na ideia de colaboração. Ele detecta, a partir da década de 1990, a emergência de projetos que "supunham a mobilização de estratégias complexas":

Esses projetos implicavam: a implementação de formas de colaboração que permitiram associar durante tempos prolongados (alguns meses no mínimo, alguns anos em geral) a números grandes (algumas dezenas, algumas centenas) de indivíduos de diferentes proveniências, lugares, idades, classes, disciplinas; a invenção de mecanismos que permitissem articular processos de mobilização de estados de coisas locais (a construção de um parque, o estabelecimento de um sistema de intercâmbio de bens e serviços, a ocupação de um edifício) e de produção de ficções, fabulações e imagens, de maneira que ambos os aspectos se reforçassem mutuamente; e o planejamento de dispositivos de publicação ou exibição que permitissem integrar os arquivos dessas colaborações de modo que pudessem se tornar visíveis para a coletividade que as originava e se constituir em materiais de uma interrogação sustentada, mas também circular nessa coletividade aberta que é a dos espectadores e leitores potenciais. Um número crescente de artistas e escritores parecia começar a se interessar menos em construir obras do que em participar da formação de ecologias culturais. ${ }^{19}$

${ }^{18}$ LADDAGA. Estética da emergência, p. 29.

${ }^{19}$ LADDAGA. Estética da emergência, p. 11, grifo do autor. 
O livro se dedica a analisar alguns desses projetos: Park fiction, que se definia como "uma produção colaborativa de desejos" e foi uma aliança entre artistas, moradores e arquitetos que se opôs a um projeto de especulação imobiliária num bairro de Hamburgo $;^{20}$ o projeto de Liisa Roberts, vinculado à restauração de uma biblioteca projetada por Alvar Aalto em Vyborg e que acabou por reunir oficina de escrita, a produção de um filme, uma vivência pelas ruas da cidade, modificações no edifício e envolveu a cidade toda; ${ }^{21}$ o projeto Venus, iniciado pelo artista Roberto Jacoby, que se tornou um projeto de intercâmbio de bens e serviços artísticos ou não e que tem até moeda própria; ${ }^{22} \mathrm{e} o$ de $\mathrm{Wu}$ Ming, na Itália, um grupo que se propunha a ativar processos de escrita colaborativa que incluíssem os leitores e, mais intensamente, construir uma mitologia para o movimento de processo global. ${ }^{23}$

Esses projetos se articulam menos na produção de obras (embora a maior parte produza objetos estéticos como filmes, que são premiados em festivais; embora Wu Ming edite seus livros e os disponha na Amazon, por exemplo) do que "na exploração de modos experimentais de coexistência de pessoas e de espaços, de imagens e tempos, suas ações." ${ }^{24}$ Arriscando uma explicação conjuntural para a mudança de cultura que afirma estar ocorrendo, Laddaga aponta as mudanças sofridas pela instituição da arte, a transformação das formas de circulação da arte, a crise do aparato de edição, provocada pelas grandes fusões, enfim, aquele processo conhecido como globalização. A produção de uma incerteza global, que perturba as figuras da cidadania: "um número cada vez mais crescente de indivíduos está situado em encruzilhadas de estradas que vinculam seu território cotidiano a circuitos que se estendem a perder de vista, em cujo desenvolvimento se desfaz a associação de comunidade e proximidade."’25

${ }^{20}$ Cf. Park Fiction Project. Disponível em: http://park-fiction.net/park-fictionintroduction-in-english/. Acesso em: 03 jul. 2019.

${ }^{21} \mathrm{Cf}$. What's the Time in Vyborg? The Counter-Restoration of a Functionalist Monument. Disponível em: http://muse.jhu.edu/article/515316/pdf. Acesso em: 03 jul. 2019.

${ }^{22}$ Cf. Proyecto Venus: en busca de nuevas formas de vida. Clarin. Revista N. Disponível em: https://www.clarin.com/ideas/proyecto_venus-_en_busca_de_nuevas_formas_de_ vida_0_B1keXdt2wme.html. Acesso em: 03 jul. 2019.

${ }^{23} \mathrm{Cf}$. Che cos'è la Wu Ming Foundation. Disponível em: https://www.wumingfoundation. com/giap/. Acesso em: 03 jul. 2019.

${ }^{24}$ LADDAGA. Estética da emergência, p. 50.

${ }^{25}$ LADDAGA. Estética da emergência, p. 59. 
E, com Karin Knorr Cetina, ele lê um presente que duvida dos valores modernos para além da sua imbricação com a arte:

Porque o presente não só é uma época em que os processos de individualização característicos do moderno se aprofundam decisivamente, mas é também uma época em que "os seres humanos competem com os objetos como parte de uma relação e entornos de situação." Entretanto, este "presente é o momento em que talvez pela primeira vez na história recente fica pouco claro se, para os indivíduos, outras pessoas são a parte mais fascinante do seu entorno", quando pela primeira vez se verificam formas de relação que "envolvem 'relações de objeto' com coisas não humanas que competem com - e até certo ponto - substituem as relações humanas. ${ }^{.26}$

Os projetos que são exemplos da emergência do Regime Prático, e que em última instância o fundamentam,

se integram na exploração desse presente evidente, buscando modos de coexistência, de convivência, nos quais os valores estéticos da obra de arte são menos buscados, ou são buscados longe do primeiro plano. No lugar do ideal de escrita, por exemplo, coloca-se o ideal da improvisação. ${ }^{27}$

Em outro de seus livros, Estética de laboratório: estratégias das artes no presente, de 2010 (Estética da Emergência é de 2006), Laddaga toca em um ponto crucial, a meu ver:

É comum que os indivíduos padeçam, no que concerne às coletividades, de uma ambivalência: por um lado, percorreos uma vontade de se incorporar a formações coletivas, mas ao mesmo tempo são singularmente sensíveis aos efeitos indesejáveis dessas formações. ${ }^{28}$

${ }^{26}$ LADDAGA. Estética da emergência, p. 62. São dois os textos citados: KNORR CETINA. Transitions in knowledge societies, p. 620; e KNORR CETINA; BRUGGER. The Market as an Object of Attachment: Exploring Postcolonial Relations in Financial Markets, p. 141.

${ }^{27}$ LADDAGA. Estética da emergência, p. 159.

${ }^{28}$ LADDAGA. Estética de laboratório: Estratégias das artes do presente, p. 27. 
E, com o sociólogo peruano Danilo Martuccelli, afirmará que no presente a consciência individual dos indivíduos nunca foi tão social e que sua experiência do social nunca foi tão individual. Nesse livro ele se dedica às formas de falar de si e o que o interessa nesse projeto é a vida observada, o autor falando de sua experiência no mundo, com a literatura, mas também com a performance e as artes.

Aqui também, e anos depois de ter conceituado o Regime Prático, Laddaga quer inventariar formas de compreensão de uma mudança de paradigma, mas não mais em termos de coletividades e sim numa cena íntima: "um artista se expõe enquanto realiza uma operação em si mesmo." ${ }^{29}$ De novo aparece, porém de outro modo, a ruptura com o moderno (não fala nesse livro nos termos de Rancière, quebra do Regime Estético):

Como muitos, creio que vivemos em tempos em que as formas institucionais, organizacionais e ideológicas constituídas desde metade do século XIX, e que até pouco tempo definiam os marcos de nossa vida comum, perdem sua integridade e definição: vivemos no possível final da época das sociedades. ${ }^{30}$

O capítulo final se dedica à questão da validez do termo Pósmodernismo, a partir de Jameson, mostrando sua insuficiência para pensar a arte do presente.

Por que o termo Pós-modernismo perde a validade? Substancialmente porque tenta descrever uma totalidade sem brechas. Laddaga sustenta que para Jameson o Pós-modernismo era o "momento em que se desenvolvia no espaço social inteiro, sem que restassem regiões não afetadas, um princípio de dissociação ou separação." ${ }^{31}$ Os artistas se ausentariam totalmente de suas produções, sem expressar seus estados emocionais e sem dizer nada das circunstâncias em que as obras foram criadas. Essa forma de pensar o presente (na década de 1980) deu lugar a esse pensamento que os autores com os quais estou trabalhando neste texto combatem: a leitura desesperançada ou acusativa de um "espaço social inteiro", um tempo homogêneo, o da banalização do consumo - do

\footnotetext{
${ }^{29}$ LADDAGA. Estética de laboratório: Estratégias das artes do presente, p. 13.

${ }^{30}$ LADDAGA. Estética de laboratório: Estratégias das artes do presente, p. 21.

${ }^{31}$ LADDAGA. Estética de laboratório: Estratégias das artes do presente, p. 210.
} 
mercado para otários como diz Compagnon em Os cinco paradoxos da modernidade -, um poder global sem saídas.

Os autores e obras abordados por Laddaga nesse livro contrariam uma a uma as propensões de Jameson:

O artista pós-moderno, dizia Jameson, é o artista da "ironia neutra" ou da "escrita branca": o indivíduo que produz expressões isentas das marcas do processo material que as originaram, do fato de que foram compostas nesse ou naquele lugar do mundo por esse ou aquele indivíduo ou grupo de indivíduos. Mas isso, precisamente isso, é o que os artistas e escritores que estive analisando se obstinam em não fazer: os objetos ou eventos que propõem incluem, em geral, descrições ou manifestações não só de como chegaram a se compor, mas também das condições do entorno daqueles que os executaram e que se apresentam, então, como pessoas situadas em um espaço concreto e em uma rede de relações, pessoas que são pontos de relativa fixidez nos que impactam correntes que nem sempre entendem. ${ }^{32}$

Mas tudo isso, porém, não indica uma maneira nova, um regime novo, de estar no presente, e sim, um prolongamento de uma das linhas da tradição moderna: "a propensão a pensar que uma obra de arte verdadeiramente crítica deve realizar uma explicitação minuciosa de suas condições." ${ }^{33} \mathrm{O}$ que difere a produção do presente da moderna é a "velocidade de precipitação" que essa tendência teria experimentado nas últimas décadas. A valorização crescente da vontade de o artista se mostrar em sua nudez. Laddaga não se dedicará aos reality shows, aos "espetáculos do eu", à produção ligada à mídia, e sim à cena intimista na qual o que se dá não é o espetáculo, mas o estúdio, a observação de si pelo artista e não pelo grande público.

Assim, para além das evidências da emergência de algo tão radical como a arte colaborativa ou que valoriza a experiência, a vivência - ou talvez seja melhor dito, mais permeada por um valor ético que estético, porém não como função e sim como desejo: o desejo de uma ética ainda permanece como uma das tendências das artes no tempo em que vivemos, uma literatura de matriz moderna. O Regime Prático, afinal, não sucederia - e portanto - não aboliria o Regime Estético. Isso é no

${ }^{32}$ LADDAGA. Estética de laboratório: Estratégias das artes do presente, p. 211.

${ }^{33}$ LADDAGA. Estética de laboratório: Estratégias das artes do presente, p. 212. 
mínimo perturbador. Pois a afirmação mesma de um novo regime é a de uma ruptura de paradigma, de uma mudança de episteme.

Mas o contemporâneo (termo que evita as catastróficas visões do "pós-modernismo") não é o tempo da convivência conflituosa de todas as tendências?

Em outro de seus livros, Espectáculos de realidad, de 2007, Laddaga se dedicou ao que ele chama de performances de autores que estão mais interessados em construir fragmentos de mundo, dar a ver processos em andamento, no desenvolvimento de uma prática. Lê isso como tendência do presente, no qual, como já afirmava em Estética da emergência, os artistas estão menos interessados na produção de obras, em se dedicar a contar uma história, que a de exibir procedimentos. César Aira, Mário Bellatin e João Gilberto Noll estão entre os autores estudados. Sua leitura passa por uma ideia de transformação de um imaginário da literatura moderna. De certo modo, poderíamos dizer, uma transformação de uma das tendências da literatura moderna, porque, pelo menos a de César Aira, se constitui na tensão com os ideais modernos, notadamente os das vanguardas. De todos os modos, o que Laddaga sempre detecta é uma relativização dos valores estéticos em prol de experiências na arte e no corpo do artista, em sua exposição e em seu modo de interferir na instituição literária ou artística. Mas não seria esse, ainda, o gesto por excelência das vanguardas? E é justamente aí que reside a inovação: a construção de uma literatura que deseja ser arte contemporânea. A partir dessa premissa, Laddaga aponta cinco variações para a expressão de Walter Pater ("all art aspires to the condition of music") que definiriam essa literatura contemporânea que interessa mapear em livro como evidências de uma modificação no modo de conceber a literatura no presente: "toda a literatura aspira à condição de arte contemporânea"; "toda a literatura aspira à condição de improvisação"; "toda a literatura aspira à condição de fotografia"; "toda a literatura aspira à condição do mutante"; "toda a literatura aspira à condição de transe". ${ }^{34}$

Sandra Contreras, na introdução de seu livro Em torno al realismo y otros ensayos, "Derivas rancierianas hacia lo real", chama a atenção para o fato de que, ao ler a produção do presente, Rancière se dedica às outras artes, nunca à literatura: "até onde sei, Rancière não se ocupa de

${ }^{34}$ LADDAGA. Espectáculos de realidad, p. 14-15. 
literatura contemporânea." ${ }^{35}$ Suas leituras da literatura são aquelas que instituem o paradigma estético - ou moderno, se se quiser. Flaubert, especialmente. Sua ideia de literatura, evidencia Contreras, como aparece em La palabra muda, é "forma necessária" e "conteúdo indiferente".

$\mathrm{O}$ que Contreras, a exemplo de Laddaga, deseja confrontar em Rancière é a reafirmação da distância estética como principal atributo da arte do presente - a afirmação de uma política das artes que está em seu próprio modo de fazer e de se dar a ver, numa ideia sempre em torno da eficácia estética, este o cerne do Regime Estético. Porém, o que ambos sustentam, a partir de caminhos de pesquisa distintos, é que a arte do presente privilegia outros valores ao colocar em segundo plano a produção final da obra e se interessar mais pelo processo.

Em Espectáculos de realidad, que Laddaga diz ter sido escrito concomitantemente a Estética da emergência e sendo, portanto, "práticas complementares da mesma interrogação", ${ }^{36}$ ele aponta para outro tipo de valor:

Estas atividades parecem estar orientadas por uma finalidade, digamos, ético-política: um traço importante do processo é a valorização, em ambos os casos, de tudo aquilo que incremente a vida associativa, ao mesmo tempo que a propensão a inventar modos inéditos de associação. De modo que por algum tempo me pareceu que uma maneira de descrever o que faz um número crescente dos escritores mais jovens é dizer que suas ações se propõem obedecer a certo "imperativo categórico" que se pode formular desta maneira: opera de tal modo que teu exercício das letras possa articular-se explicitamente com práticas destinadas a incrementar as formas da solidariedade em espaços locais. ${ }^{37}$

As atividades a que se refere são as dos autores jovens que escrevem no início do milênio tanto no México e na Argentina como no Brasil. São escritores que pensam que o momento central de sua prática é a performance. O livro foi pensado a partir de uma passagem de Noite

35 "hasta donde sé, Rancière no se ocupa de literatura contemporânea". CONTRERAS. En torno al realismo y otros ensayos, p. 27, tradução minha.

${ }^{36}$ LADDAGA. Espectáculos de realidad, p. 23.

${ }^{37}$ LADDAGA. Espectáculos de realidad, p. 16-17, tradução minha, grifo do autor. 
deflores, de César Aira, logo associado a Mário Bellatin e a João Gilberto Noll. Em três países, três escritores dando mostras de uma atividade que coloca em cena o exibir-se em seus livros e também o processo de escrita, em espetáculos de realidade e, a partir deles, se pode mapear muitos casos que dão conta dessa tendência da literatura contemporânea que ele diz ser a dos "escritores ambiciosos" ${ }^{38}$ Ambiciosos porque estão investindo na "criação de realidades" no dizer já bastante conhecido de Josefina Ludmer em "Literaturas pós-autônomas."

É interessante perceber que Laddaga investiga o presente contra a ideia de Pós-modernidade e também busca furar a ideia de um Regime Estético sem mudanças a partir da Modernidade, ou seja, afirmando rupturas, mas não nos termos já existentes, sem, no entanto, ir à discussão do tema do contemporâneo enquanto conceito. A partir mesmo dos subtítulos dos seus livros que expressam o desejo de investigação da literatura atual, percebe-se que ele evita o uso do termo: "Espectáculos de realidad. Ensayo sobre la narrativa latinoamericana de las dos últimas décadas"; "Estética de laboratório: Estratégias das artes do presente". A evitação da designação de "contemporâneo" para a literatura do tempo em que vivemos evidencia de maneira ainda mais clara a reserva do seu uso somente para a arte: toda literatura aspira à condição de arte contemporânea.

Se ingressamos, assim, em algo como um Regime Prático das artes, penso, ele estaria nomeando de forma nova aquilo que designamos como "o contemporâneo": a consolidação de um certo consenso em torno da impossibilidade de se identificar uma única tendência, fazendo coexistirem diferentes concepções, estratégias e usos da arte e da literatura. Um consenso mínimo de afirmação do dissenso: contra o tempo global, os diversos tempos das pessoas; contra a grande luz, os pequenos clarões de todas as intensidades e cores; contra o panorama, as pequenas imagens. Por todo lado furos, brechas, rachaduras. Estratégias dissonantes que não permitem, ou pelo menos dificultam a identificação da arte, da literatura, naquilo já instituído.

\section{Referências}

AGAMBEN, Giorgio. O que é o contemporâneo? e outros ensaios. Tradução de Vinícius Nicastro Honesko. Chapecó: Argos, 2009.

${ }^{38}$ LADDAGA. Espectáculos de realidad, p. 20.

${ }^{39}$ LUDMER. Aqui América latina: Una especulación. 
CONTRERAS, Sandra. En torno al realismo y otros ensayos. Rosário: Nube Negra ediciones, 2018.

DIDI-HUBERMAN, Georges. Sobrevivência dos vaga-lumes. Tradução de Vera Casa Nova e Márcia Arbex. Belo Horizonte: Editora UFMG, 2011.

KNORR CETINA, Karin. Transitions in knowledge societies. In: BENRAFEL, Eliezer; STERNBERG, Itzak (ed.). Identity, Culture and Globalization. Amsterdam: Brill, 2001.

KNORR CETINA, Karin; BRUGGER, Urs. The Market as an Object of Attachment: Exploring Postcolonial Relations in Financial Markets. Canadian Journal of Sociology, Edmonton, v. 25, n. 2, p. 141-168, 2000.

LADDAGA, Reinaldo. Espectáculos de realidad: Ensayo sobre la narrativa latinoamericana de las dos últimas décadas. Rosario: Beatriz Viterbo Editora, 2007.

LADDAGA, Reinaldo. Estética da emergência: a formação de outra cultura das artes. Tradução de Magda Lopes. São Paulo: Martins Fontes, 2012.

LADDAGA, Reinaldo. Estética de laboratório: estratégias das artes do presente. Tradução de Magda Lopes. São Paulo: Martins Fontes, 2013.

LUDMER, Josefina. Aqui América latina: Una especulación. Buenos Aires: Eterna Cadencia Editora, 2010.

RANCIÈRE, Jacques. A partilha do sensível. Tradução de Mônica Costa Neto. São Paulo: Editora 34, 2005.

RANCIÈRE, Jacques. Em que tempo vivemos? Tradução de Donaldson M. Garschagen. Revista Serrote, São Paulo, n. 16, p. 203-222, mar. 2014.

RANCIÈRE, Jacques. O dissenso. Tradução de Paulo Neves. In: NOVAES, Adauto. A crise da razão. São Paulo: Companhia das Letras, 1996.

RANCIÈRE, Jacques. O espectador emancipado. Tradução de Ivone C. Benedetti. São Paulo: Martins Fontes, 2014.

RANCIÈRE, Jacques. Política da literatura. Tradução de Renato Pardal Capistrano. A!, Rio de Janeiro, v. 5, n. 5, p. 110-131, jan./jul. 2016.

Recebido em: 30 de janeiro de 2019. Aprovado em: 3 de julho de 2019. 